\title{
ITS Solution IN RAILWAY Signalization, Control And Traffic Management
}

\author{
Matulic, M., Musa, M. \& Perakovic, D.
}

Abstract: Railway signalization through history evolved, from written instructions to the engine-man, to the traffic directed from signalling equipment, which is controlled by ITS telematics device. This way of using telematics provides us with a better and safer usage of railway infrastructure. The combination of the mastermind who can remotely manipulate all the traffic and traffic operated locally in stations which are communicating with each other gives us an efficient and safe system. The basic and most important advantage with controlling signalling elements though printed boards is in the direct detection of failure of elements installed outside and which are included in railway traffic. This paper examines actual situation on Croatian railway network and importance of implementation a new ITS based paradigms for signalisation, control and traffic management.

Key words: railway, traffic, safety, interlocking, ITS
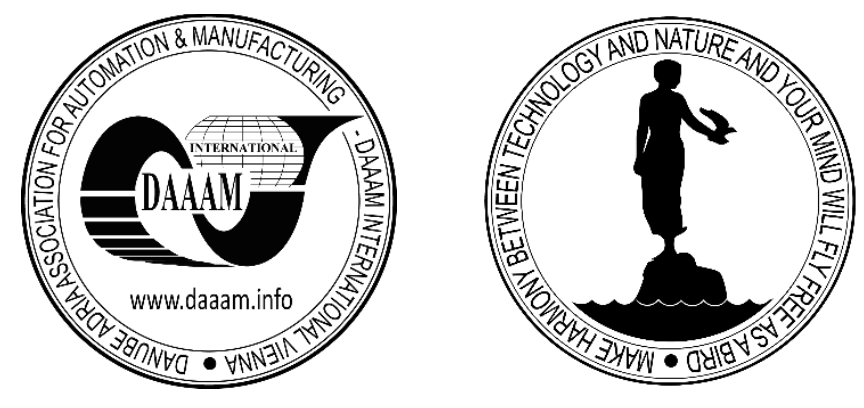

Authors' data: Matulic, I[gor]*; Musa M[ario]**, Assoc. Prof. Perakovic, D[ragan] ${ }^{* * *} ; *$ M. V. M. Zvon d.o.o., Topnicka 4, 10000 Zagreb, Croatia; ** Pružne građevine Ltd., Međimurska 4, 10000 Zagreb, Croatia; ***Faculty of Transport and Traffic Sciences, Vukelićeva 4, 10000 Zagreb, Croatia

This Publication has to be referred as: Perakovic, D[ragan]; Matulic, I[gor] \& Musa, M[ario] (2016). Its Solution in Railway Signalization, Control and Traffic Management, Chapter 35 in DAAAM International Scientific Book 2016, pp.393-406, B. Katalinic (Ed.), Published by DAAAM International, ISBN 978-3-902734-09-9, ISSN 1726-9687, Vienna, Austria

DOI: 10.2507/daaam.scibook.2016.35 


\section{Introduction}

Intelligent Transport System (ITS) are advanced applications which aim to provide innovative services relating to different modes of transport and traffic management and enable various users to be better informed and make safer, more coordinated, and 'smarter' use of transport networks. In railway network different telematics solutions (e.g. interlocking) are in place or in testing phase related to management and control of railway network. The main issue of the paper is how to improve traffic safety on railway network through signalling and control equipment, and traffic management system. As railway interlocking is a safety critical system, hence it requires advanced formal modelling techniques and step-by-step development to ensure safety, quality and reliability of the system. Interlocking is the most important component of a signalization system, which ensures safe travel and transportation (Y1ldirım et al., 2012).

The purpose of railway interlocking system is to prevent trains from collisions and derailing while at the same time allowing normal train's movement (Haxthausen et al., 2008). There are various types of interlocking systems, in practice, varying from purely mechanically operated to state-of-the-art computerized moving block interlocking systems. Fixed block and moving block interlocking are two main types of interlocking. Moving block is gaining more important in railway industry due to some disadvantages in fixed block interlocking system. A railway interlocking system controls the train in a railway station, and between adjacent stations. The control includes train routes, shunting moves and the movements of all other railway vehicles in accordance with railway rules, regulations and technological processes required for the operation of the railway station. Maintainability by its definition is the probability that a given active maintenance action, for an item under given conditions of use, can be carried out within a stated time interval (Begović, 2003). Maintenance needs to be performed under stated conditions and using stated procedures and resources (Thereg \& Vlasenko, 2009).

Different types of interlocking maintenance and its procedures are modified to gain the best efficiency in the time slot foreseen for maintaining a specific item or group of items. Detection of failure evolved from visual detection in Mechanical Interlocking through indication on the Operators panel in the local station to immediate detection in a dislocated maintenance centre which monitors the whole track for a set of telematics interlocking. When researching and collecting data, the inductive method was used, whereas desk research includes development and use of these systems in Europe and Croatian railway network and importance of implementation a new ITS based paradigms in railway traffic management.

\section{Classifications of interlocking devices}

Interlocking devices are a part of railway infrastructure and from that point of view their evolution, from traffic operated by human who controlled and manipulated all of the preconditions for allowing trains to pass to the system with electronic interlocking which has full control of the traffic, is natural. Interlocking systems are 
used as decision-making mechanisms in railway systems in order to prevent potential accidents so that trains travel on railway safety (Svendsen et al., 2008). Operators are now in the function of moderating the traffic through a system in which all of the safety procedures and rules are incorporated through software. This type of system can easily and quickly process all of the information from outside elements which are gathered with accuracy. This way of collecting and processing data avoids the possibility of human error. The basic precondition is that all of the rules for specific railway philosophy are accurately transferred into software which controls traffic safety through hardware and outside elements. Safety represents the basic philosophy of railway traffic and as such all of the interlocking technologies must incorporate elements to ensure safety of the system. All of the elements, which are included in the interlocking, must therefore be properly maintained. Technical equipment, in which all the safety protocols are incorporated through knowledge, mechanical bars, locks, relays or elements for redundancy can be grouped into basic types of interlocking as follows: human or manual (traffic is operated without any technical support), mechanical (electromechanical) and telematics (electric and electronic). Software design of the interlocking systems can be performed by different methods such as automaton method, petri nets, etc (Dincel \& Kurtulan, 2012).

\section{Main functions of interlocking}

The interlocking is described as a system which operates through three levels. The first level can be described as the Human Machine Interface - HMI (operational level). The second level is the decision making level (interlocking level) and the third level is the executive level (element control level).

\subsection{Operational level}

On this level (Fig. 1., section A), operators manage the traffic from a local station or from the Centralized Traffic Control, through the HMI. In most cases both solutions are possible. Setting the routes, switching points, shunting, track closing and other similar actions are performed here. The basic difference between these two ways is that from the CTC the operator has the possibility to influence an increase of traffic capacity and he becomes a moderator of the timetable.

Electronic components provide the possibility that a much larger amount of data can be processed and transmitted in a matter of seconds so then all of relevant data regarding trains, rolling stock, stations, tracks, disturbances, planned construction work, availability restrictions, blockings, speed restrictions, timetables and train connections is permanently and automatically processed and visualized (***, 2008). With this solution occurring conflicts and delays are displayed to the operator and he can decide which actions should be taken to maintain the time-table. It is much easier to preserve a satisfying quality level of service with an automatic update of arrival times through Passenger Information Systems and changing departure times for connections. On the other hand, operators are irreplaceable in local stations for setting and controlling shunting routes. 
Perakovic, D.; Matulic, I. \& Musa, M.: Its Solution in Railway Signalization, Contr...

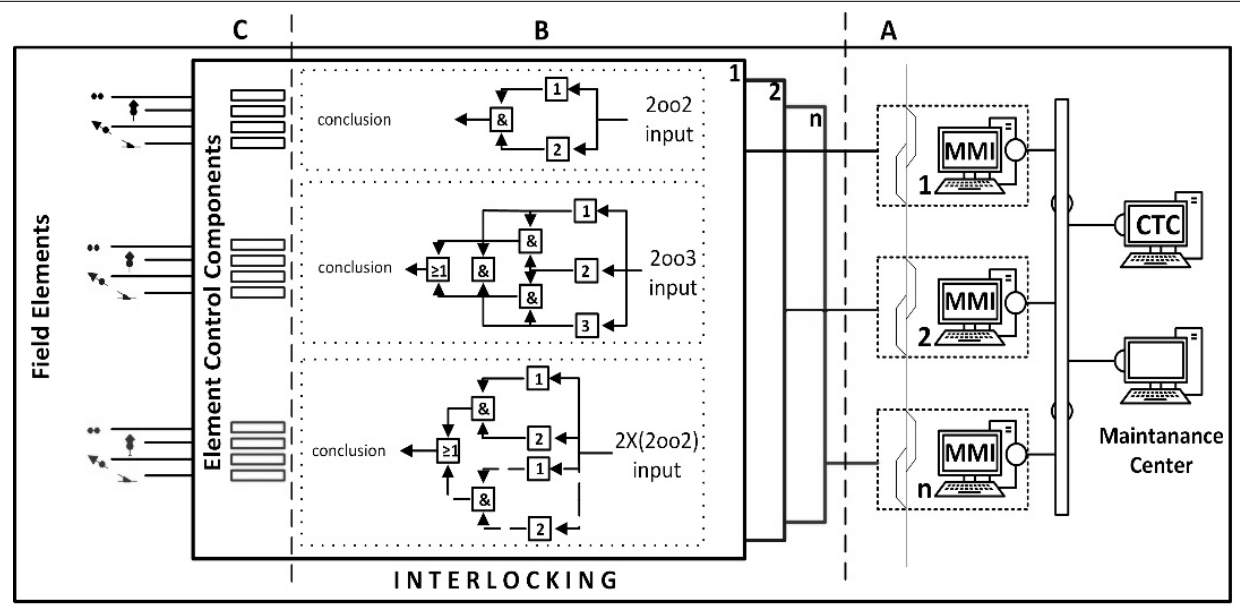

Fig 1. Geographical and functional structure of an electronic interlocking

\begin{tabular}{|l|l|l|l|}
\hline $\begin{array}{l}\text { Interlocking } \\
\text { technologies }\end{array}$ & $\begin{array}{l}\text { Operational } \\
\text { level }\end{array}$ & Interlocking level & $\begin{array}{l}\text { Element } \\
\text { control level }\end{array}$ \\
\hline Human & - & $\begin{array}{l}\text { Human (to be } \\
\text { reminded by the } \\
\text { signaller) }\end{array}$ & $\begin{array}{l}\text { Human } \\
\text { (walking } \\
\text { between the } \\
\text { elements) }\end{array}$ \\
\hline $\begin{array}{l}\text { Mechanical } \\
\text { interlocking }\end{array}$ & $\begin{array}{l}\text { Mechanical } \\
\text { levers }\end{array}$ & $\begin{array}{l}\text { Mechanical (level } \\
\text { frame) }\end{array}$ & $\begin{array}{l}\text { Mechanical } \\
\text { (wires or rods) }\end{array}$ \\
\hline $\begin{array}{l}\text { Relay } \\
\text { interlocking }\end{array}$ & $\begin{array}{l}\text { Electric buttons } \\
\text { and } \\
\text { illuminations }\end{array}$ & Electric (relays) & Electric \\
\hline $\begin{array}{l}\text { Electronic } \\
\text { interlocking }\end{array}$ & $\begin{array}{l}\text { Electronic } \\
\text { (monitor, } \\
\text { mouse or tablet, } \\
\text { keyboard) }\end{array}$ & $\begin{array}{l}\text { Electronic } \\
\text { (hardware/software) }\end{array}$ & Electronic \\
\hline
\end{tabular}

Tab 1. Basic interlocking technologies and technical application of these functions (Thereg \& Vlasenko, 2009).

\subsection{Interlocking level}

On this level the decision making takes place. All of the philosophy of a certain railway, regulations and safety conditions must be incorporated in the software or in relay logic. Figure 1, section B shows the logical structure incorporated into the hardware. The electronic system is safe when hardware and software redundancy and diversity is used. Reasons for this lie in its components which are sensitive to outside electromagnetic influence, they have no preferred direction of failure, and they can change characteristics over time. To exclude systematic errors in production because of the complexity of production and detection of changes on printed boards, diversity is used. To maintain the operability of the system if the result of one electronic subsystem is not expected, safety redundancy takes place:

- 2 out of 2 (20o2) system can be described as a system in which safety functions are processed through two independent channels and the result is compared. 
Both results should be identical for an action to take place. In case of different results the system goes to safe state.

- 2 out of $3(2003)$ system is a system in which three independent subsystems give a result. If one is different, this result is ignored and the system reacts as 2002 .

- $2^{*}(2002)$ one redundant subsystem is active and the other works in standby mode. If a failure occurs in the active subsystem then the redundant system takes over.

\subsection{Element control level}

Element control level communicates and commands the outside elements. The basic principle is shown in Fig. 1., section C. Through communication information transmission goes to and from a specific element. This is used for two purposes. One is to see the state of a certain element; the other is to command it to perform some action in route setting. The advantage of this type of communication is in the constant awareness of the state of each element.

\section{Types of interlocking devices}

\subsection{Human interlocking}

First form the four types of interlocking mentioned above is the human interlocking. Safety was insured with operators knowledge of rules and his judgment. No maintenance was needed.

\subsection{Mechanical interlocking}

Mechanical interlocking functioned trough mechanical connections established through leavers on operational level. Interlocking level was lever frame. Element control level was established through rigid connection (rods, pipes) or flexible connection (wires) to the end elements. Safety strategy was to try to make mechanical components in a way that they eliminate technical failures (e.g. breaking of a leaver). Two things had the most influence on limitations for this type of interlocking: physical strength of operator (trough pure physical strength elements were adjusted to required position) and range of elements (because of temperature influence on wires, rods). With interlocking which operates traffic mechanically with moving parts of a great importance was preventive maintenance (e.g. lubrication of leavers, visual checks of mechanical parts).

Therefore, it required large scale of human force to do the maintenance. Power interlocking may also use mechanical locking to ensure the proper sequencing of levers, but the levers are considerably smaller as they themselves do not directly control the field devices. If the lever is free to move based on the locking bed, contacts on the levers actuate the switches and signals which are operated electrically or electropneumatically. Before a control lever may be moved into a position which would release other levers, an indication must be received from the field element that it has actually moved into the position requested. No disturbances could be detected via interlocking only failures while route should be stetted. 
Perakovic, D.; Matulic, I. \& Musa, M.: Its Solution in Railway Signalization, Contr...

\subsection{Telematics interlocking}

\subsubsection{Relay interlocking}

Next step was relay interlocking. Basic element of this type of interlocking is relay itself. There are three relay classes:

- First class relay (type N) which is used without monitoring of their dropping down. Those are the most expensive relays,

- Second class (type C) relay which operation should be checked with circuitry,

- Third class relays or non-signal relays which usage in safety related circuitry is forbidden.

To overcome mechanical limitations and extend control of railway elements relay interlocking was constructed. Two basic types should be distinguished:

- Free-wired type interlocking made with tabular principle,

- Interlocking assembled on a geographical principle (combined of a predefined relay groups).

Both of them use the correct choice of contacts for applying defined set of rules and limitations to ensure safety. Trough feedback from relays, sets of relays safety relevant elements was monitored and information about failures and disturbances was sent to the operator so that problem can be solved. There were limitations to the amount of maintenance teams which should cover certain region. Monitoring and storing of a system disturbances and failures on centralized location was not possible because limitations of technology.

\subsubsection{Free-wired relay interlocking}

Tabular principle is more suitable for smaller stations. All possible routes are predefined in a matrix which tells the exact position or state of each element included in a route should be. All allowed routes are defined. Operational level was done through buttons which are to be pushed, pulled or turned. Geographical position of elements is displayed on HMI and its status information is represented by control lamps. They can show status of line block, position of point, status of routes and occupation of track sections. On Interlocking level predefined routes form route locking matrix trough wired sets of relays are executing. Sets of relays, which are responsible for positioning of elements, represent element control level. It takes longer to build this type of interlocking because most of the work on whirring and testing is done on site but therefore it is easier later for maintenance but it is quite complicated for later upgrades (e.g. adding of a point, track).

\subsubsection{Relay interlocking constructed on geographical principle}

Geographical principle is more suitable for larger interlocking areas. In its basics it is constructed of standardized set of relays for each element prefabricated and tested by its producer. On site it is connected via predefined fabricated cables according to the track layout. Main advantage of this type of system is relatively easy upgrade. Operating, interlocking and element control level operates logically in the same way 
as in the free-wired system. Maintenance of the system is relatively easy, but expensive because price of relay sets.

\subsubsection{Electronic interlocking}

Tabular or geographical principle is identical as in relays interlocking as are the problems with developing the system. Difference is in the type of equipment which is used and that the logic of the system must be evolved in the laboratory. Because series of software tests must be done there is no possibility that some programming is done elsewhere. Printed boards took over operations instead of relays and relay sets which is natural evolution of the system. Maintenance and upgrading of the system is easy and costs of spare parts are lower than in the relay solutions because printed boards could be used on different positions only is important that proper software is loaded. Basic advantage of this type of interlocking is that large amount of system data can be monitored and stored on centralized location. In this way maintenance can be more efficiently done and errors could be reduced to a minimum with proper reaction to the disturbances. It provides more efficiently error solving which is of a great importance to the traffic itself.

\section{Outage and safety prevention}

Outage of the system could be distinguished between two states. Disturbance is defined as deviation from the specified performance of a system due to external influences (Thereg \& Vlasenko, 2009). Failure is deviation from specific performance. A failure is the consequence of a fault or error in the system. When a disturbance appears then by its logic the system must go to safe state by Fail Safe Principles (basic principle of safe systems), in which any kind of assumable failure must lead to a safe situation. This may result in severe traffic disruption or other inconveniences (Haramina et al., 2012), (Haramina et al., 2011), (Thereg \& Vlasenko, 2009). After failure the system goes to a full stop mode.

Outage of interlocking system could cause collision and derailing that are defined as (Zahar et al., 2012):

- existence of two trains on a track segment is a collision;

- existence of two trains on a crossing is a collision;

- when a train is at level crossing and barriers are open, is a collision;

- if direction of a train and state of a switch do not match, it may cause derailing. Based on these definitions, the safety properties can be stated as:

- There must be, at most, one train at one track segment and crossing to avoid collision.

- Barriers must be closed when a train is at level crossing to avoid collision between train and road traffic.

- A train must respect state of a switch control preventing derailing.

There are several ways to avoid potentially dangerous situations and reduce to a minimum the possible situations when a disturbance and failure can appear. One of them is preventive maintenance which is defined by safety regulations and is done 
periodically according to prescribed procedures for all the types of interlocking devices described in chapter 4 . In an electronic interlocking system self-testing can and must take over a certain amount of preventive maintenance. This way, maintenance personnel can react much faster. All of the data from self-testing can be transmitted via a closed network to the maintenance center for analysis. The principle of the maintenance center is the same as CTC, but its communication goes only one way. Information can be provided only to the maintenance center which must have a block scheme of the monitored line with all of the stations. A zoom function must be available all the way to the element control level because all of the elements must have a unique ID which can be called upon. As railway interlocking is a safety critical system, we have analysed railway passenger fatalities to compare the implementation of telematics solutions and other improvements in railway network that have been done in past decades (especially while implementation of electronic equipment has started in late 80 's) with the fatalities rate. Nonetheless, the moving national averages of train passenger risks also show that these risks tend to decay in each EU-28 country, which allows the development of the overall passenger fatality risk for the total railway system in the EU to be analysed. The fatality risk per billion train passenger kilometer fell from 1970 to 2005 by an average of $5.5 \%$ per year, derived from the fitted exponential risk decay model (UIC, 2012).

The annual number of train passenger fatalities in the EU decreased from about 400 in the early 1970s to around 100 in 2000 and further decreased to 66 in 2005 . The rail passenger kilometre in the EU-nations increased from about 330 billion in 1970 to about 380 billion in 2005. In 2010 the annual number of train passenger fatalities in the EU continued with further decrease from 63 (407 billion PKm) to 36 in 2012 (419 billion PKm) (European Commission, 2014).

\section{Traffic Management System}

Interlocking's, including line block systems, are the traditional instrument in the signaling sub-system used to interconnect information on the status of elements and commands issued to various control devices. Over the decades, an evolution has taken place from manual to automated functioning, with a move from mechanical, electromechanical or relay-based systems to electronic computer-based technology. Extremely high safety and reliability levels have always been key requirements. Safety of European railways can be significantly enhanced through integration of modernised technology (Smith et al., 2012). In many European railway networks, there is a huge potential need for renewal of heritage signaling installations, including their interlocking's. However, an economic analysis of several railways show that a renewal at current cost levels for planning, procurement and implementation is no longer affordable [1].

It should be highlighted that throughout history all railways have protected themselves by their own statutes and regulations as well as equipment technical specification, which governed traffic management. The first limiting factor was observed by the industry as a factor which blocks the railway and makes it less competitive, by enhancing the price of transport, which indirectly affected the railways 
alone as well. Thus ERTMS was developed as a joint project of leading rail equipment manufacturers. Interoperability systems enable a smooth transport between countries, thus increasing the competitiveness as well as rail transport safety. Total exploitation of rail network infrastructure is achieved through interoperability, which is a basis for ITS respectively ERTMS system. Intelligent transport systems improve transportation infrastructure. Their implementation is very important, because of their positive effects on traffic safety, efficiency and reducing costs (Janušová \& Čičmancová, 2015).

\subsection{ERTMS - common signalling and communication system}

Railways act in a competitive environment and have to provide operating security, international interoperability, increase of transport capacities as well as reduction of travel times and reduction of equipment life cycle costs. Nowadays the European railways have to deal with at least six (6) different rail electrification types and approx. 20 different traffic controls and management systems. Each of them is extremely expensive in terms of maintenance and management. It occupies space on command board of the locomotive - it is complex and presents an additional cost in terms of cross-border traffic. This limits the competition and hinders the competitiveness of the European railway sector vis-à-vis road traffic by creating technical obstacles to international journeys $(* *, 2014)$.

ERTMS (European Railway Traffic Management System) has two basic components: ETCS (European Train Control System) is an automatic train protection (ATP) and control system, which shall substitute the existing national ATP systems and GSM-R (Global System for Mobile Communications - Railway), radio system for providing voice and data communication between track and train, is based on GSM standards by applying separate frequencies for rail applications with specific features and advances functions. With ETCS, the track sends data to the train, thus enabling that its highest speed limit is continuously calculated. On routes, where there is a signalization available by the track (lights and traffic signs make it possible for the driver to know the speed limit), this information can be sent by means of standard signalling equipment (Eurobalise), situated by the track.

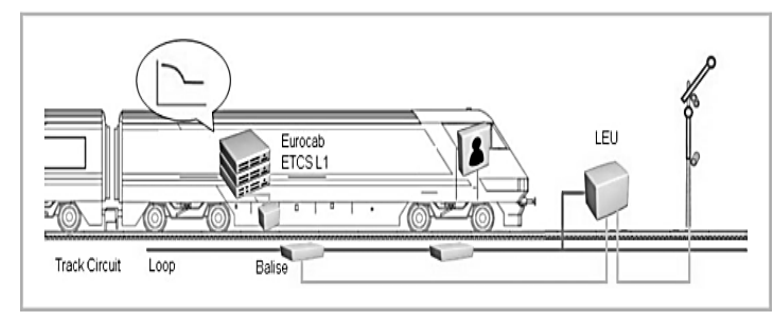

Fig. 2. Level one ETC System

This is known as ETCS - level 1. For ETCS - level 2, the information can also be forwarded via radio (GSM-R). In this particular case, it is not necessary to keep track signals, but they are kept for redundancy reason and fall back option. Communication media are Eurobalise and GSM-R. The position of trains at this level is still being 
Perakovic, D.; Matulic, I. \& Musa, M.: Its Solution in Railway Signalization, Contr...

detected by means of track signals. The position of trains at this level is still being detected by means of track signals. Ultimately, for ETCS - level 3, the train alone sends its current position, which enables the optimization of railway line capacities and additional track equipment reduction. At all levels, train-computer (the so-called Eurocab) compares the speed of the train with maximum speed and automatically reduces the speed of the train if the speed has been exceeded.

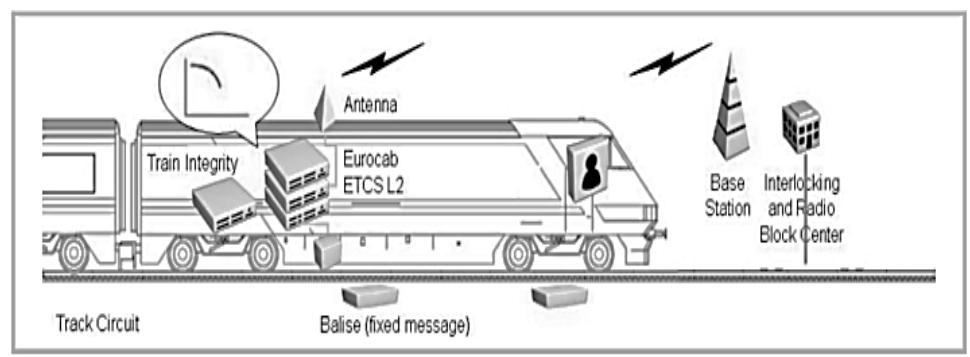

Fig. 3. Level three ETC system

GSM-R is a part of ERTMS standard and conveys information on signalization directly to train signalization unit, providing for higher speed of train and traffic density at high safety level. GSM-R is based on public GSM and provides a rich variety of features dealing with specific needs of rail operators. The railway was allocated for GSM-R 19 channels in frequent bands $876-915 / 921-960 \mathrm{MHz}$ and cannot act as public network for security reasons because it may not be influenced from the outside. Technical specifications and standards are drawn up with UIC within EIRENE project (European Integrated Railway Radio Enhanced Network). In order to achieve interoperability across Europe by applying one communication platform, GSM-R standard combines all key functions and experiences from 35 analogue systems used across Europe.

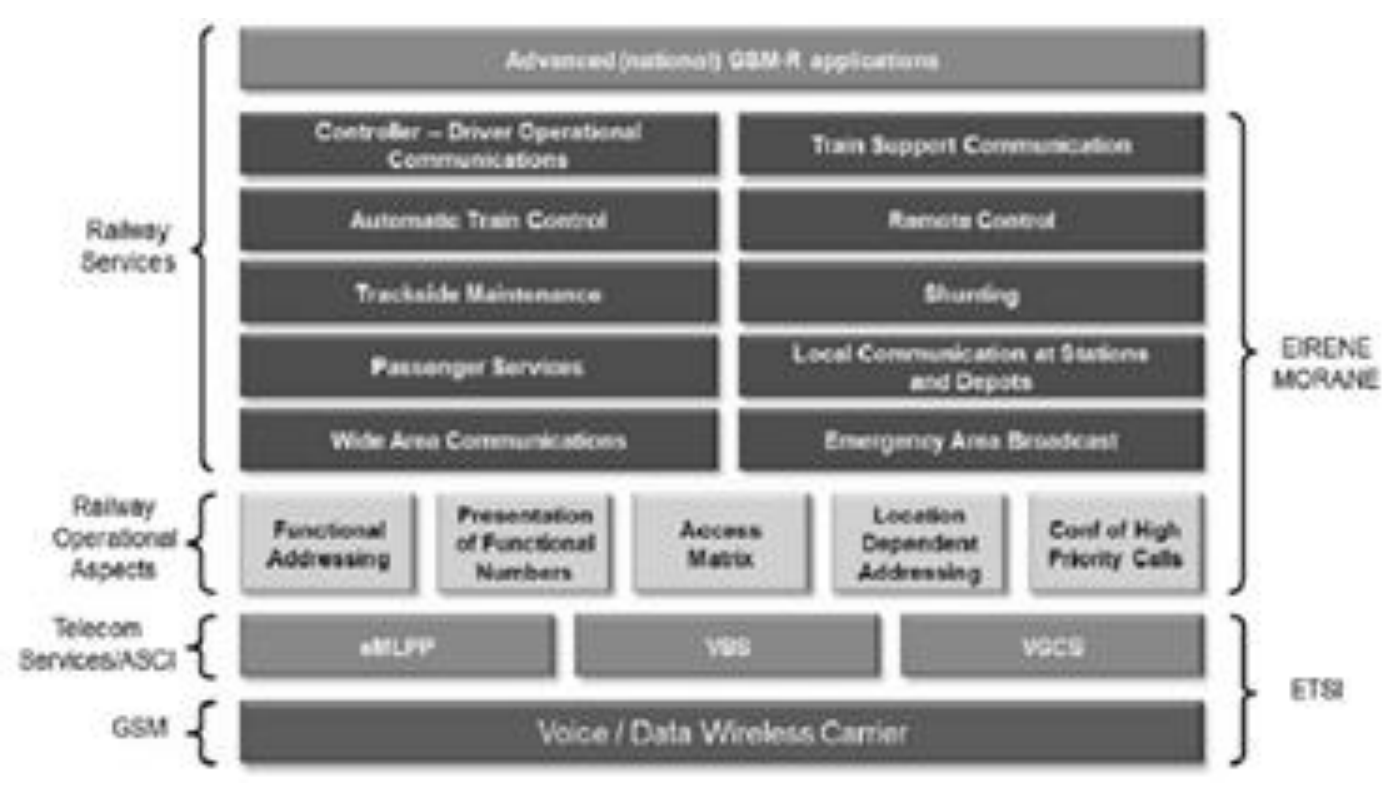

Fig. 4. Scope of services to be provided by GSM-R network 
GSM-R provides a safe platform for voice and data communication between operating staff of railway companies, including train driver, link centre, members of switch staff, railway station and engineers and train controllers. The system provides advanced possibilities such as group calls, voice broadcasting, location-based linkage as well as emergency calls, which considerably improves communication, co-operation and management safety via operating staff members.

\subsection{ERTMS and interlocking's in practice}

It was not until the end of the 80's that the electronic systems were installed. At present, mainly relay and electronic devices are being used in Europe. On all new railway lines as well as those lines, which are being refurbished to meet the ECTS standards, mainly electronic devices are being installed. We believe it is possible to use a relay device within ECTS levels. However, this would require the development and verification of interface in terms of the appropriate SIL level. With regard to available resources, the shortage of experts in the relay technique area as well as high certification costs for each particular interface, this is not financially justified (Akillilar \& Koppe, 2008). The purpose of ERTMS is to replace various national rail traffic control and management systems in Europe (UIC, 2008). As a unique European rail traffic control and management system, ERTMS is designed for the purpose of gradually substituting the existing incompatible systems across Europe. This shall bring considerable advantages to rail sector, as well as boost international passenger transports. ERTMS is the rail traffic control and management system which brings considerable advantages in terms of maintenance cost saving, safety, reliability, punctuality and increase of traffic capacities. The purpose of ERTMS is to make rail sector, in comparison to road traffic, more competitive, which ultimately shall provide considerable gains in terms of ecology. ETCS is a traffic control and management system defined by the UIC (Union Internationale des Chemins de fer). The system is elaborated in detail for the purpose of rail traffic liberalization in order to provide rail competitiveness by means of the same system in all European countries. The system shall provide cost reduction as a result of economy of scale, reduction of costs of development as well as quality cross-border services as a result of broad compatibility between on-board control and command equipment and corresponding railway track fittings. ETCS provides a unique signalization system and paves the way for boosting cross-border operations for high-speed trains and regular trains for passenger transportation trains $(*, 2008)$.

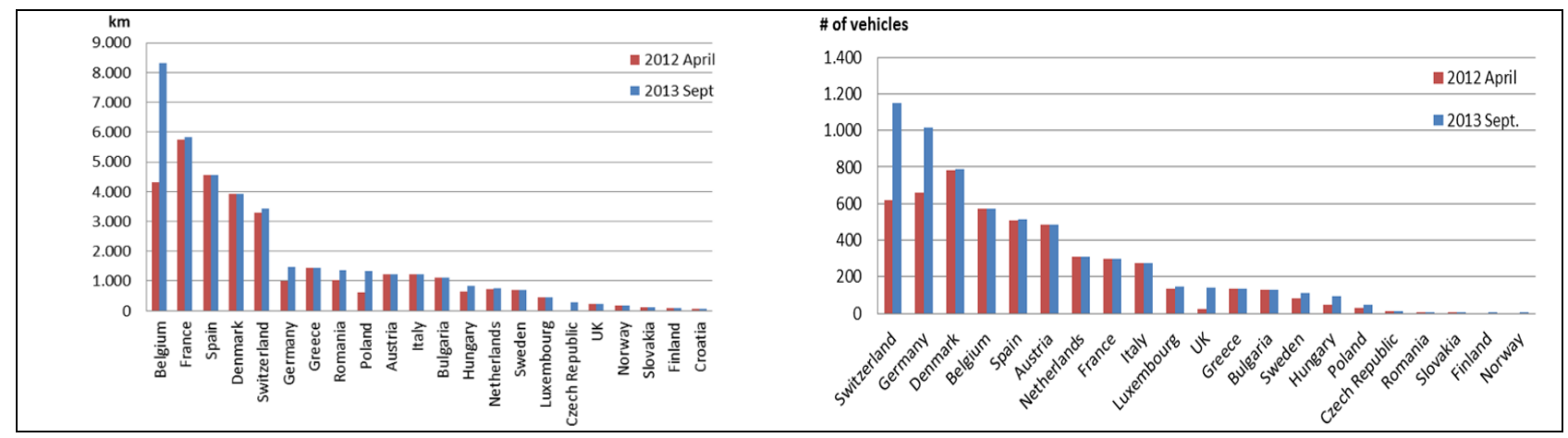

Fig. 5. ERTMS investment in Europe (trackside km and number of vehicles) Source: UNIFE 
In the Republic of Croatia, there is a certain number of mechanical devices, which are being refurbished until new traffic management devices are installed. Those new devices shall be either relay or electronic devices, as it is no longer allowed to install new mechanical devices. On all corridor routes in the Republic of Croatia, relay or electronic devices are installed or in the process of being installed. The devices which are being installed are more than 30 years old, which implies that the modernization of signaling and safety systems, including further modernization of communication systems (GSM-R), is essential. Traffic regulation on the network of Croatian Railways is regulated by remote control dispatcher from remote control center only on Vinkovci - Tovarnik and Okucani-Novska route section (X. corridor) that is equipped with remote control devices, and ETCS system - level 1 is built in on this track section. However, it is not used because not a single traction vehicle of Croatian Railways has any equipment for ETCS. This system is useful if the entire section is equipped with Eurobalise, traction vehicles which run on that section by means of locomotive ETCS devices. Otherwise, a „dual mode" traction vehicle equipment is indispensable for conventional ATP and ETCS, which considerably enhances the price of the vehicle performance alone. At present, there is no automatic traffic management system available on rail network in Croatia. Deployment of the speed control component (ETCS) is slower. However, 6000 kilometers are already equipped or are in the process of being equipped. Projects are under way in almost all European countries (**,2014).

GSM-R has not been implemented anywhere on the network of Croatian Railways yet. In Europe, GSM-R can now be deployed very rapidly, and according to data from the UIC, the GSM-R deployment in Europe in 2012 was as follows: out of the 154284 $\mathrm{km}$ of track planned to be equipped with GSM-R in Europe, $85332 \mathrm{~km}$ of track are with GSM-R installed (55.30\% of the planned network) and $70211 \mathrm{~km}$ of track are in operation (45.5\% of the planned network), 40130 Cab Radios and 1900 ETCS Data Only Radios are activated $(* *, 2014)$.

\section{Conclusion}

Comparing relay interlocking with electronic it is easy to see natural evolution to smarter solution as it was from mechanical to relay. Due to relay interlocking electronic is more efficient because it gives us more information which we can use at the same time. It gives us possibility to have better overview of the system especially trough dealing with Errors, Failures and Disturbances which represent safety principles in railway operation. On a railway we have two participants involved in one route (we have a train driver and operator for each train route), safety of the traffic is or should be ensured by the interlocking which must react safely.

Preserving basic safety requirement that in case of errors, failures and disturbances persons, goods and environment must not be exposed to risks is much easier when you have certain amount of data processed quickly through processor (two or three working at the same time) than have a decision made by a human. Guided by the safety principles through history interlocking evolved from traffic controlled by humans to traffic controlled by electronic. In this way the factor of human error, which was mostly responsible for all of the critical and dark scenarios, is reduced to a 
minimum. Railway companies that are eager to be successful have to sell their tailormade services to potential customers. Likewise, they have to provide high-level quality service at eligible price. First of all, the modernization of signaling and safety systems, including the modernization of communication systems and network is a prerequisite.

This is followed by the implementation of ITS solutions - traffic control and management system in accordance with ERTMS standards, which aims to improve rail transport networks, and improve the quality and safety of the transportation. From the aforementioned arises the fact that primarily it is necessary to modernize signaling systems including the modernization of communication systems - implement GSM-R on tracks of importance for international and regional traffics in order to provide a broad range of services provided for by this technology.

In further development of railway transport network is necessary to introduce ETCS 1 on tracks of importance for regional traffic and ETCS 2 for international traffic. Analogue with the aforementioned, traction vehicles should also be equipped with ECTS devices and the entire section with Eurobalise. Due to the fact that it is impossible to implement this on the entire network for economic and financial reasons, „dual mode" equipment for traction vehicles is indispensable for regular ATP and ETCS equipment. The purpose of all of this is to boost traffic by rail and to make it more competitive, which ultimately shall provide considerable gains in terms of ecology, as well as social and economic gains.

Paper shows the course of system development of signalization, control and traffic management in railway, based on new ITS paradigm. All of the above should result in higher operating safety, international operability, and increase of transport capacities, punctuality and reliability, reduction of management and maintenance costs as well as reduced travel times.

\section{References}

Akillilar, M., Koppe, C. (2008). Increase of effectiveness and efficiency in the interlocking system ESTW L90 5, Signal und Draht, vol.100, no.4, DB AG, Eurailpress, Hamburg, Germany

Begović, M. (2003). Telematics Systems Maintenance, Faculty of Transport and Traffic sciences, University of Zagreb, ISBN 953-6790-79-3, Zagreb

Dincel, E., Kurtulan, S. (2012). Interlocking and Automatic Operating System Design with Automaton Method, Proceedings of the 13th IFSC Symposium on Control in Transportation Systems, The International Federation of Automatic Control, Stoilov, T. (Ed.), pp.191-196, ISBN 978-392823-13-7, Sofia, Bulgaria, September 2012 European Commission (2014). EU transport in figures, Publications Office of the European Union, ISBN 978-92-79-37506-4, Belgium

Haramina, H., Brabec, D, Grgic, D. (2012). Influence of train control system on railway track capacity, In: DAAAM international scientific book 2012, Katalinić, B. (Ed.), pp. 419-426, DAAAM International Publishing, DAAAM International Vienna, ISBN 978-3-901509-86-5, Vienna 
Perakovic, D.; Matulic, I. \& Musa, M.: Its Solution in Railway Signalization, Contr...

Haramina, H., Brabec, D., Stefancic I. (2011). Influence of train control system characteristic on railway infrastructure capacity. Annals of DAAAM for 2011 \& Proceedings of the 22nd International DAAAM Symposium, Katalinić, B. (Ed.), pp. 357-358, ISBN 978-3-901509-83-4, Vienna, Austria, November 2011

Haxthausen, A. E., Bilguet, M. L., Kjaer, A. (2008). Modeling and Verification of Relay Interlocking Systems, Proceedings of the 15th Monterey Workshop, Choppy, C., Sokolsky, O. (Ed.), pp. 141-153, ISBN 978-3-642-12565-2, Budapest, Hungary, September 2008

* http://ec.europa.eu/transport/modes/rail/interoperability/ertms/ - European Commision - ERTMS, Accessed on: 2014-07-23

** http://www.ertms.net/?page_id=49 - ERTMS History, Accessed on: 2014-08-05

Janušová, L., Čičmancová, S. (2015). Improving Safety of Transportation by Using Intelligent Transport Systems. Proceedings of the 9th International Scientific Conference, pp. 14-22, Vilnius, Lithuania, May 2015

Smith, P., Majumdar, A., Ochieng, W. Y. (2012). An overview of lessons learnt from ERTMS implementation in European railways. Journal of Rail Transport Planning \& Management, Vol. 2, Issue 4, (December 2012) pp. 79-87, ISSN: 2210-9706

Svendsen, A., Olsen, G. K., Endersen, J., Moen, T., Carlson, E., Alme, K. J. (2008). The Future of Train Signaling, Proceedings of the 11th International Conference MoDELS, Czarnecki, K., Ober, I., Bruel, J. M., Uhl, A., Völter, M. (Ed.), pp. 128-142, ISBN: 978-3540-87874-2, Tolouse, France, September 2008

*** Thales Security Solutinos \& Services, NetTrac 6613 ARAMIS, www.thalesgroup.com/security-services, THALES, Stuttgart, Germany, 2008.

Thereg, G., Vlasenko, S. (2009). Railway Signalling \& Interlocking, Eurailpress, ISBN 978-3-7771-0394-5, Hamburg

UIC (2008). ETCS Implementation Handbook, ERTMS Platform, Infrastructure Department, ISBN 2-7461-1499-2, Paris

UIC, International railways statistics, 2012.

Yıldırım, U., Durmuş, M. S., Söylemez, M. T. (2012). Automatic Interlocking Table Generation for Railway Stations using Symbolic Algebra, Proceedings of the 13th IFSC Symposium on Control in Transportation Systems, The International Federation of Automatic Control, Stoilov, T. (Ed.), pp. 12-14, ISBN: 978-3-902823-13-7, Sofia, Bulgaria, September 2012

Zahar, N. A., Khan, S. A., Araki, K. (2012). Towards the Safety Properties of Moving Block Railway Interlocking System. International journal of innovative computing, Information and Control, Vol. 8, No. 8, (August 2012) pp. 5703-5713, ISSN 13494198 